\title{
Motivation and martial arts and combat sports participation: a study protocol
}

\author{
António SILVA* \& António QUARESMA \\ Universidade Lusófona de Humanidades e Tecnologias, Faculdade de Educação Física e Desporto \\ (Portugal)
}

\begin{abstract}
Martial arts and combat sports (MA\&CS) popularity has been growing, and their associated benefits are widely known. Several studies report psychological benefits related to MA\&CS participation. Albeit there is a broad body of research (following the tenets of self-determination theory - SDT) on motivation in sport and exercise, research in MA\&CS motivation is scarce or very specific to single disciplines or styles. The objective of this study is to understand the motivational mechanisms for adherence and retention on MA\&C practice, to identify differences between MA\&CS on participants' basic psychological needs and the quality of their motivational regulation. Mediation analysis will be conducted to explore the mechanisms of motivation on MA\&CS participation.
\end{abstract}

Keywords: Martial arts; combat sports; self-determination theory; motivation; physical activity adherence and retention; mediation analysis.

\section{Introduction}

Martial arts and combat sports (MA\&CS) popularity has been growing during the last decades, and the associated benefits for their practitioners, such us improved overall health and increased sense of wellness (Bounty, Campbell, Galvan, Cooke, \& Antonio 2011), are widely known. They can be an option for doing physical activity (PA), providing a set of formal movements that can be used for practicing self-defense, sports competition, physical conditioning, or motor and emotional skills (Koutures \& Demorest, 2018). Several studies report psychological benefits related to MA\&CS participation (e.g., Chyu, 2010; Jansen P. \& Dahmen-Zimmer, 2012; Chyu et al., 2013; Lip et al., 2015). Fabio and Towey (2018), in a cross-sectional study with two independent groups of MA\&CS and non-MA\&CS practitioners, reported that the MA\&CS group, even when differentiated by experience level, showed higher levels of self-esteem and self-efficacy and lower levels of aggressiveness than the control group. Another study exploring the motives for practicing krav maga and wing chung identified self-defense and physical conditioning as the main goals and related them with the development of autonomy and competence, in the scope of selfdetermination theory (SDT), underlining, however, the need for further studies on motivation variables (Körner, Heil, \& Staller, 2017). Ryan, Frederick, Lepes, Rubio and Sheldon (1997) compared different motivations between aerobics and taekwondo participants and concluded that motives related to the body was more associated to aerobic participants and fun and competence were more associated to taekwondo participants. Albeit there is a broad body of research (following the tenets of SDT) on motivation for sport and exercise, research in MA\&CS motivation is scarce or very specific to single disciplines or styles.

\section{Objectives}

The objective of this study is to understand the motivational mechanisms for adherence and retention on MA\&C practice, to identify differences between MA\&CS on participants' basic psychological needs and the quality of their motivational regulation. 


\section{Methodology}

We will conduct this study between 2019 and 2020, with a cross-sectional observational design, using a web-based self-reported data form. Our sample will be comprised of at least 1,000 participants from the top twelve most participated Portuguese MA\&CS. In the first part of our inquiry we will collect general demographic data and MA\&CS historical data of participation for each subject. On the second part of the inquiry we will assess motivation with the Psychological Need Satisfaction in Exercise Scale (Wilson, Rogers, Rodgers, \& Wild, 2006) and the Behavioral regulation in Exercise Questionnaire 3 BREQ3p in the Portuguese Version (Palmeira, Teixeira, Silva, $\&$ Markland, 2007). Pearson correlations, independent-sample $t$-test, analyses of variance (ANOVA), and mediation analysis (Hayes, 2013) will be conducted to explore the mechanisms of motivation on MA\&CS participation.

\section{Results, Discussion and Conclusion}

In terms of motivational regulation, we expect to find positive associations between adherence and retention to MA\&CS and the more intrinsic components of motivation on the noncompetitor participants. In line with SDT, we also expect to find greater satisfaction and less frustration of basic psychological needs on the overall sample (Ryan \& Deci, 2017). We also intend to explore the mechanisms by which different MA\&CS, with distinct formal and cultural frameworks, have distinct motivational components. On the other hand, in terms of basic psychological needs, we expect to find significant differences between individuals with different experience in practicing MA\&CS. This study will allow us to compare different MA\&CS in terms of motivational regulation and basic psychological needs by exploring demographic variables and their indirect influence on MA\&CS participation.

\section{References}

Chyu, M. C., Zhang, Y., Brismée, J. M., Dagda, R. Y., Chaung, E., Von Bergen, V., ... Shen, C. L. (2013). Effects of martial arts exercise on body composition, serum biomarkers and quality of life in overweight/obese premenopausal women: a pilot study. Clinical medicine insights. Women's health, 6, 55-65. doi: 10.4137/CMWH.S11997

Chyu, M.-C. (2010). A non-competitive martial arts exercise program for health and fitness in the general population. Journal of Human Sport and Exercise, 5(3), 430-443. doi: $10.4100 /$ ihse.2010.53.13

Fabio, R. A., \& Towey, G. E. (2018). Cognitive and personality factors in the regular practice of martial arts. Journal of sport medicine and physical fitness, 58(6), 933-943. doi: 10.23736/S0022-4707.17.07245-0

Hayes, A. F. (2013). Introduction to mediation, moderation, and conditional process analysis: $A$ regression-based approach. New York: The Guilford Press.

Jansen P. \& Dahmen-Zimmer, K. (3 de 2012). Effects of cognitive, motor, and karate training on cognitive functioning and emotional well-being of elderly people. Frontiers In Psychology, p. 40 .

Körner, S., Heil, V., \& Staller, M. S. (2017). Motive in der Selbstverteidigung: Eine qualitative und quantitative Studie am Beispiel Krav Maga und Wing Chun. In S. Körner, \& L. Istas (Eds.), Martial Arts and Society: Zur gesellschaftlichen Bedeutung von Kampfkunst, Kampfsport und Selbstverteidigung (pp. 146-159). Feldhaus, Edition Czwalina.

Koutures, C., \& Demorest, R. (2018). Participation and Injury in Martial Arts. Current Sports Medicine Reports, 17(12), 433-438. doi: 10.1249/ISR.0000000000000539

Bounty, P. L., Campbell, B. I., Galvan, E., Cooke, M., \& Antonio, J. (2011). Strength and Conditioning Considerations for Mixed Martial Arts. Strength \& Conditioning Journal, 33(1), 56-67. doi: 10.1519/SSC.0b013e3182044304

Lip, R. W., Fong, S. S., Ng, S. S., Liu, K. P., \& Guo, X. (2015). Effects of Ving Tsun Chinese martial art training on musculoskeletal health, balance performance, and self-efficacy in communitydwelling older adults. Journal of physical therapy science,27(3), 667-672. doi: 10.1589/jpts.27.667 
Palmeira, A. L., Teixeira, P., Silva, M. N., \& Markland, D. (2007). Confirmatory Factor Analysis of the Behavioural Regulation in Exercise Questionnaire - Portuguese Version. 12th European Congress of Sport Psychology Halkidiki, Greece.

Ryan, R. M., \& Deci, E. L. (2017). Self-Determination Theory: Basic Psychological Needs in Motivation, Development, and Wellness. New York: The Guilford Press.

Ryan, R. M., Frederick, C. M., Lepes, D., Rubio, N., \& Sheldon, K. M. (1997). Intrinsic motivation and exercise adherence. International Journal of Sport Psychology, 28(4), 335-354.

Wilson, P. M., Rogers, W., Rodgers, W. M., \& Wild, T. (2006). The Psychological Need Satisfaction in Exercise Scale, Journal of Sport and Exercise Psychology,28(3), 231-251. doi: 10.1123/jsep.28.3.231 